
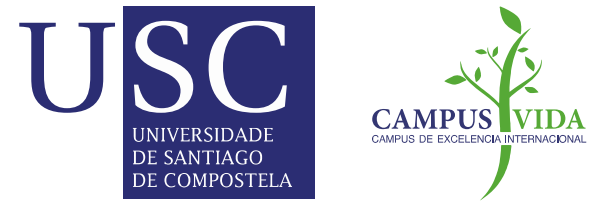

\title{
Spatially Controlled Supramolecular Polymerization of Peptide Nanotubes by Microfluidics
}

Alejandro Méndez-Ardoy, Alfonso Bayón-Fernández, Ziyi Yu, Chris Abell, Juan R. Granja, Javier Montenegro

\section{Supplementary information}

\section{Copyright information:}

(c) 2020 WILEY-VCH Verlag GmbH \& Co. KGaA, Weinheim 


\title{
Supplementary Information for Spatially Controlled Peptide Nanotube Fibrillation by Microfluidics
}

\author{
Alejandro Méndez-Ardoy, ${ }^{\mathrm{a}}$ Alfonso Bayón-Fernández, ${ }^{\mathrm{a}}$ Ziyi Yu, ${ }^{\mathrm{b}}$ \\ Chris Abell, b Juan R. Granja, ,a Javier Montenegro*,a
}

${ }^{a}$ Centro Singular de Investigación en Química Biolóxica e Materiais Moleculares (CIQUS), Departamento de Química Orgánica, Universidade de Santiago de Compostela, 15782 Santiago de Compostela, Spain. bepartment of Chemistry,University of Cambridge, Cambridge CB2 1EW, UK. 


\section{Contents}

$\begin{array}{lr}\text { S1 Experimental section } & 3\end{array}$

S2 Self-assembly of CP1 by charge screening $\quad 5$

S3 Diffusion of chemical species in the microfluidic device $\quad 6$

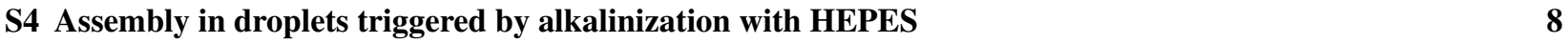

S5 Self-assembly of CP1 within water-in-oil droplets by picoinjection of $\mathrm{NaOH} \quad 9$

S6 Confocal planes for droplets where fiber formation was triggered with $\mathrm{NaOH}$ or $\mathrm{CaCl}_{2} \quad 10$

S7 Effect of flow rate changes using $\mathrm{NaOH}$ or $\mathrm{CaCl}_{2} \quad 11$

S8 References $\quad 12$ 


\section{S1 Experimental section}

Materials Reagents were acquired from Fluka, Aldrich, Iris Biotech or TCI. Pico-Surf ${ }^{\mathrm{TM}}$ was purchased from Sphere Fluids. Compound CP1 was prepared as described elsewhere.[1]

General methods The microfluidic device was produced via soft lithography by using poly(dimethylsiloxane) (PDMS) along with crosslinker (Sylgard $184^{\mathrm{TM}}$ elastomer kit, Dow Corning). Briefly, elastomer and curing agent were mixed in a ratio 10:1, thorougly mixed and pured into the master. The mixture was degassed until no bubbles were visible, then cured in the oven at $70{ }^{\circ} \mathrm{C}$ overnight. The elastomer was cut into pieces with a sharp razor and holes punched with a $1 \mathrm{~mm}$ diameter biopsy punch (kai medical). Glass slides and PDMS chips were treated with oxygen plasma for 10 seconds, then brought to contact and gently pressed. Bonding was completed by heating the chips at $120^{\circ}$ for $1 \mathrm{~h}$. The chips channels were treated with a solution of trichloro $\left(1 H, 1 H, 2 H, 2 H\right.$-perfluorooctyl)silane $1 \%$ in HFE-7500 $3 \mathrm{M}^{\mathrm{TM}}$ Novec $^{\mathrm{TM}}$ for a few seconds, then rinsed with fresh HFE-7500, and finally dried with a stream of Ar. Silanization was completed by heating the devices at $65^{\circ} \mathrm{C}$ overnight. Solvent pumping was carried out with syringe pumps (New Era NE-4002X double microfluidics syringe pump) through bore polythene tubing (Portex, $0.38 \times 0.35 \mathrm{~mm}$ ).

Preparation CP1 droplets by microfluidics Cyclic peptide CP1 $(1 \mathrm{mM})$ solutions were prepared in milliQ water $(\mathrm{pH}$ about 4$)$ and were thoroughly sonicated (30-60 min). The oil phase was prepared by diluting the original PicoSurf ${ }^{\mathrm{TM}}$ solution to a concentration of $0.5 \% \mathrm{v} / \mathrm{v}$. The formation of droplets was visualized through a high-speed Fastcam Mini camera coupled to a Nikon Eclipse Ti2. The device used is shown in Figure 1 of the manuscript. The size of the channels were $35 \times 50 \mu \mathrm{m}$. The oil was injected at a flow rate of $500 \mu \mathrm{L} / \mathrm{h}$. The peptide was injected at a flow rate of $200-150 \mu \mathrm{L} / \mathrm{h}$, and the triggering solutions at $100 \mu \mathrm{L} / \mathrm{h}$ unless otherwise specified. Droplets were collected over Novec $^{\mathrm{TM}}$ containing $0.5 \%$ v/v Pico-Surf ${ }^{\mathrm{TM}}$.

Preparation of water-in-oil droplets of CP1 for picoinjection experiments Droplets of CP1 in milliQ water intended for pico-injection experiments were prepared in a X-junction chip. The size of the channels were $40 \times 40 \mu \mathrm{m}$. The flow rates of the oil was $500 \mu \mathrm{L} / \mathrm{h}$ and the aqueous phase at $250 \mu \mathrm{L} / \mathrm{h}$.

Picoinjection of $\mathrm{NaOH}$ solutions to water-in-oil droplets containing CP1 Droplets prepared as described above were diluted with an oil stream, and piconinjection was carried out with a solution of $\mathrm{NaOH}(13 \mathrm{mM})$ using the flow rates described in Figure S7. To add the base of $\mathrm{NaOH}$ to water-in-oil droplets, the droplets of $\mathbf{C P 1}$ were then reinjected into a picoinjection microfluidic device[2] (Figure S6). Droplets were spaced by two oil inlet channels, and flowed towards a T-shaped junction, where a channel containing an aqueous solution of $\mathrm{NaOH}$ was injected continuously (see ESI Video S1 for details). A high voltage square waveform was applied between two electrodes positioned either side of the junction, causing fusion between a microdroplet and aqueous solution of $\mathrm{NaOH}$. The content of each microdroplet is then evenly mixed as it passes through a meandering channel before exiting the device. The subsequent self-assembly process of $\mathbf{C P 1}$ took place in each microdroplet independently.

STEM measurements Cu grids (300 mesh, coated with carbon grid, Ted Pella) were used to deposit the samples at concentration as obtained from the microfluidic chip outlet. Samples were stained with $15 \mu \mathrm{L}$ gadolinium acetate (2\%) and dried overnight. STEM images were acquired in a Zeiss Ultra Plus scanning transmission electron microscope operating at an extra high tension of $20 \mathrm{kV}$.

Fluorescence microscopy Epifluorescence measurements were carried out at room temperature using an Olympus BX51 with magnifications of 10x and 40x. All images were analyzed using ImageJ.[3, 4] Measurements of percentage of fluorescent area per droplet were carried out by converting fluorescence images into 8-bit images. Then, a grayscale threshold level was defined in order shade all the fibers present in the droplets. Circle areas were defined manually in 20 randomly picked individual droplets, and the percentage of fluorescence in each droplet was measured.

Fluorescence spectroscopy experiments Fluorescence measurements were carried out in a Varian Cary Eclipse fluorescence spectrophotometer. Fluorescence spectra were acquired at $20^{\circ} \mathrm{C}$ with an averaging time of $0.5 \mathrm{~s}$.

Circular dichroism experiments Circular dichroism spectra were acquired in a Jasco J-1100 CD spectrometer. Data was obtained at $20^{\circ} \mathrm{C}$ in a $2 \mathrm{~mm}$ light path quartz cuvette after substraction of the solvent background signal.

Laser Scanning Confocal Microscopy Confocal images were acquired using an Andor DragonFly confocal setup mounted on an Nikon Eclipse Ti-E inverted microscope. 
Preparation of cyclopeptide networks Typically, 5-10 $\mu \mathrm{L}$ of droplets suspended in HFE-7500 containing PicoSurf $^{\mathrm{TM}}(0.5 \% \mathrm{v} / \mathrm{v})$ were deposited on glass slides, then allowed to dry at room temperature for at least $15 \mathrm{~min}$. Networks were sealed with imaging spacers (Grace Bio-Labs SecureSeal ${ }^{\mathrm{TM}}$ ) and visualized under the fluorescence microscope. 


\section{S2 Self-assembly of CP1 by charge screening}

In order to study the effect of the counterions in the self-assembly of nanotubes, we carried out a comparative study of the addition of $\mathrm{NaCl}, \mathrm{CaCl}_{2}$ and $\mathrm{Na}_{2} \mathrm{SO}_{4}$ at the same calculated ionic strength. Molar ionic strength is given by Equation (S1)

$$
I=\frac{1}{2} \sum_{i=1}^{n} c_{i} z_{i}^{2}
$$

where $c$ is the concentration of the ion and $z$ the charge. Taking into account only the more concentrated species (electrolites and MES buffer), the calculated molar ionic strength for $\mathrm{NaCl}(1.5 \mathrm{M}), \mathrm{CaCl}_{2}(0.5 \mathrm{M})$ and $\mathrm{Na}_{2} \mathrm{SO}_{4}(0.5$ $\mathrm{M})$ in MES (50 mM) is about $1.55 \mathrm{M}$.

Addition of different electrolites to diluted solutions of $\mathbf{C P 1}(50 \mu \mathrm{M})$ at a fixed $\mathrm{pH}$ resulted in fluorescence and circular dichroism spectroscopic changes (Figure S1A,B). The apparition of positive CD signal attributed to the $\pi-\pi^{*}$ transition (Figure S1A) and the quenching of the pyrene monomer emission (Figure S1B) are clear indications of CP1 assembly. Additionally, the response to equimolar ionic strengths of monovalent $(\mathrm{NaCl})$ or divalent $\left(\mathrm{CaCl}_{2}, \mathrm{Na}_{2} \mathrm{SO}_{4}\right)$ electrolites indicated a clear dependence on the nature of the anion (e.g. $\mathrm{Cl}^{-} v s \mathrm{SO}_{4}^{2-}$, Figure S1A).
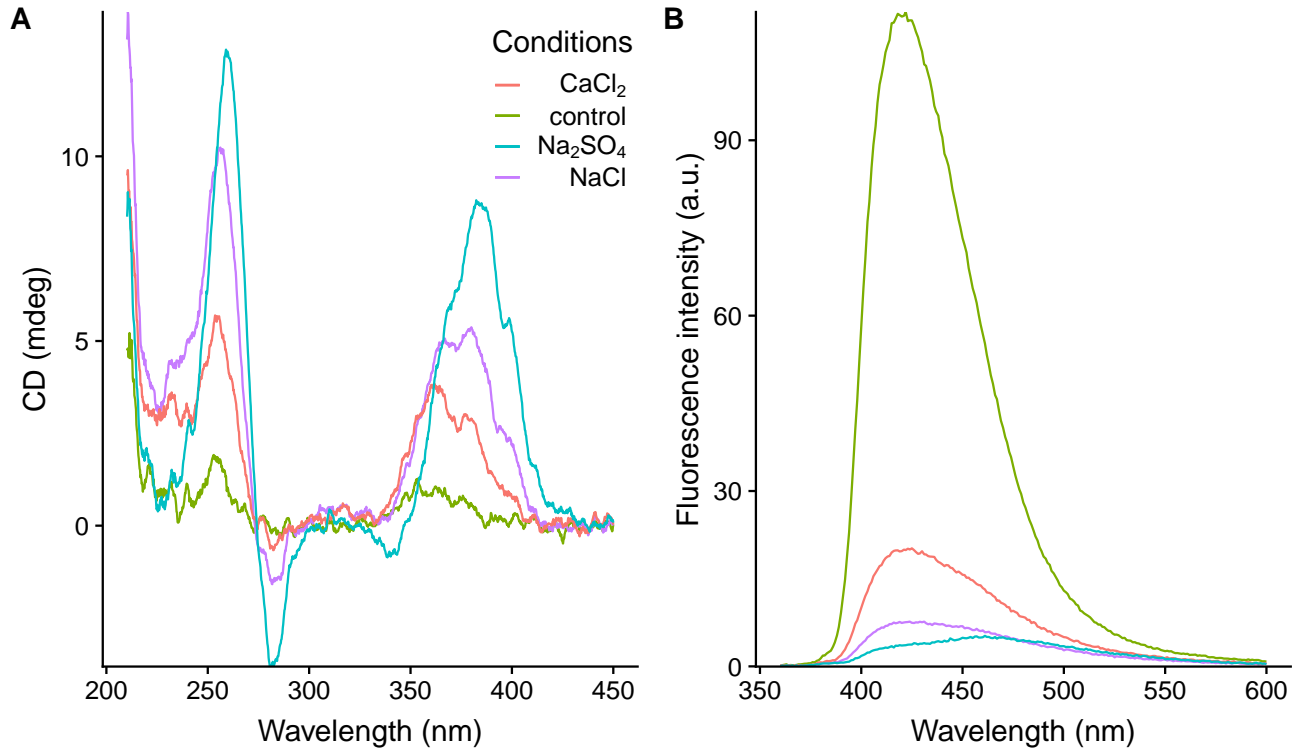

Figure S1: Assembly of CP1 $(50 \mu \mathrm{M})$ in MES $(50 \mathrm{mM}) \mathrm{pH} 5.6$ at a molar ionic strength of approximately $1.5 \mathrm{M}$. Control experiments indicate the absence of salt (green line). The electrolites were $\mathrm{CaCl}_{2}$ ( $0.5 \mathrm{M}$, red line), $\mathrm{NaCl}(1.5$ $\mathrm{M}$, purple line) and $\mathrm{Na}_{2} \mathrm{SO}_{4}(0.5 \mathrm{M}$, blue line): A) circular dichroism experiments and $\mathrm{B}$ ) fluorescence experiments, $\lambda_{e x}=340 \mathrm{~nm}$.

The assembly of supramolecular fibers were visualized under the fluorecence microscope (Figure S2), revealing higher tendency to aggregation when multivalent anions were added $\left(\mathrm{SO}_{4}^{2-}\right)$.

The formation of peptide nanotubes $\mathbf{C P 1}$ solutions with either $\mathrm{NaOH}$ or $\mathrm{CaCl}_{2}$ were visualized by STEM microscopy after gadolinium acetate[5] staining, as shows Figure S3. Stiff nanotubes were clearly visualized in all conditions, with diameters of approximately $10 \mathrm{~nm}$. This can be explained by the formation of nanotube bundles due to internanotube attractive forces such as pyrene-pyrene hydrophobic interactions or histidine-histidine hydrogen bonding. 


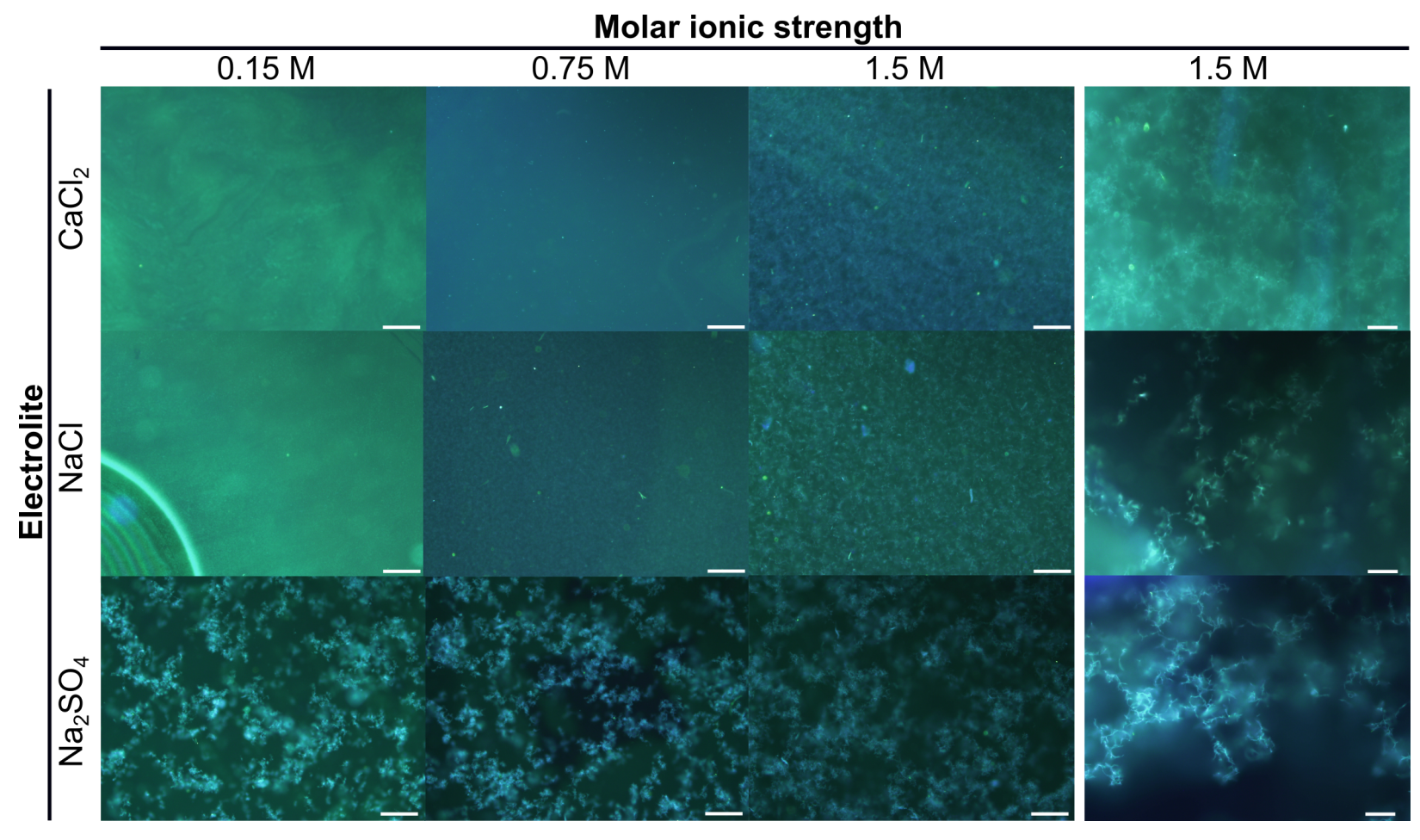

Figure S2: Effect of electrolite concentration in the self-assembly of CP1 visualized by fluorescence microscopy. Scale bars are $100 \mu \mathrm{m}$ for low magnification (left block) and $20 \mu \mathrm{m}$ for high magnification (right block).

\section{S3 Diffusion of chemical species in the microfluidic device}

In order to gain some insights into the diffusion of the chemical species within the microfluidic channels,[6] we estimated the diffusion coefficient for cyclic peptides based on reported hydrodinamic radius $\left(r_{H}\right)$ obtained for peptide dimers in our own group by DOSY experiments. Measured $r_{H}$ in $\mathrm{CDCl}_{3}$ of 3-aminocyclohexanecarboxylic acidsbased octapeptide dimers[7] gave values of $r_{H} \approx 0.7 \mathrm{~nm}$. We can estimate the diffusion coefficient in water according he Stokes-Einstein equation (Equation S2), that relates the hydrodinamic radius with the diffusion coefficient $(D)$ for particles in liquids at low Reynolds number:

$$
D=\frac{k T}{6 \pi \eta r_{H}}
$$

where $k$ is the Boltzmann constant, $T$ is the temperature and $\eta$ is the medium viscosity. Assuming a temperature of $298 \mathrm{~K}$, the diffusion coefficient in water of a octapeptide dimer is about $3.7 \times 10^{-10} \mathrm{~m}^{2} \mathrm{~s}^{-1}$. Although the expected diffusion coefficient for a monomer will be lower, the calculated value can give us an idea of the extent of diffusion within the microfluidic channel. In this sense, the Einstein-Smoluchowski-equation for planar diffusion was used to calculate the time required for the chemical species to reach the other side of the channel (Equation S3)

$$
t=\frac{d^{2}}{2 D}
$$

where $d$ was estimated as $1 / 4$ of the total microfluidic channel width $(35 \mu \mathrm{m})$ and $D$ are tabulated and estimated diffusion coefficients in water for the chemical species involved in the assembly within the microfluidic channel. The calculated times are shown in Table S1:

\begin{tabular}{c|c|c} 
Chemical species & Diffusion coefficient $\left(\mathrm{m}^{2} \mathrm{~s}^{-1}\right)$ & $t(\mathrm{~ms})$ \\
\hline \hline $\mathrm{OH}^{-}$ & $52.7 \times 10^{-10}[8]$ & 7 \\
$\mathrm{Cl}^{-}$ & $20.3 \times 10^{-10}[8]$ & 19 \\
$\mathrm{Ca}^{2+}$ & $7.92 \times 10^{-10}[8]$ & 48 \\
$\mathrm{CP}$ & $3.7 \times 10^{-10}$ & 103
\end{tabular}

Table S1: Reported and calculated diffusion coefficients of chemical species injected in the microfluidic device and calculated diffusion time for the chemical species at the interface to reach the other side of the channel 

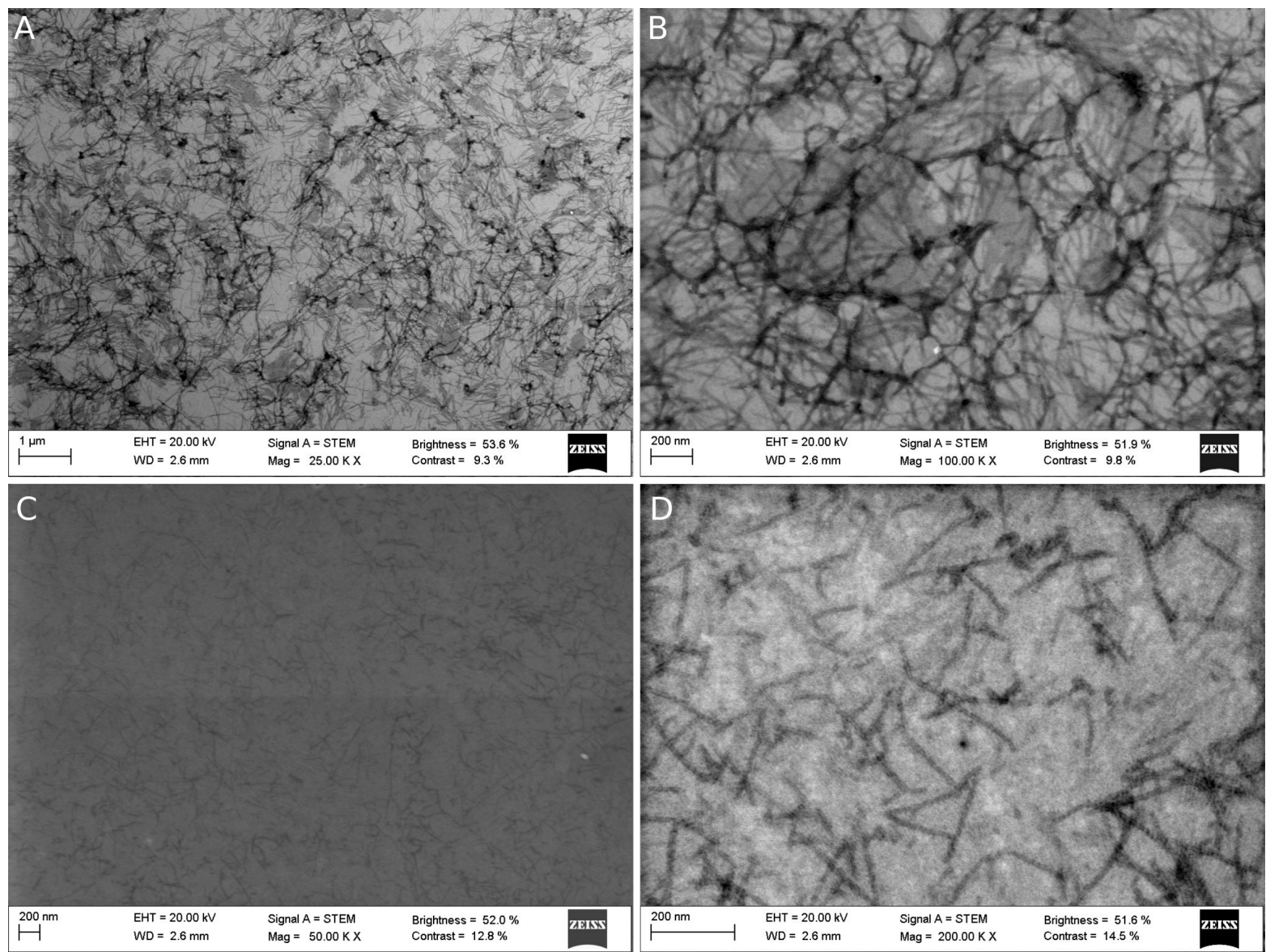

Figure S3: Formation of CP1 nanotubes when assembled by charge screening (final $\mathrm{CaCl}_{2}$ concentration approximately $500 \mathrm{mM}$ ) visualized by STEM microscopy at A) low and B) high magnification; or C) and D) assembled by using $\mathrm{NaOH} 3.5 \mathrm{mM}$

Taking into account the dimensions of the channel $(35 \mu \mathrm{m} \times 50 \mu \mathrm{m})$ and that the distance between the two junctions $J 1$ and $J 2$ is approximately $1100 \mu \mathrm{m}$, a flow rate of $350 \mu \mathrm{L} / \mathrm{h}$ will have a residence time of approximately 20 ms.

We hypothesize that assembly is initiated within the microfluidic device, but final equilibration takes place within the confined aqueous compartment. In this sense, simple theoretical calculation suggest that the diffusion of anions $\left(\mathrm{Cl}^{-}, \mathrm{OH}^{-}\right)$can reach the center of the peptide stream before reaching junction $J 2$. On the other hand, fluorescence experiments in bulk solutions indicate that equilibration occurs in more than 10 minutes (Figure S4), which suggests that equilibration can not take place within the microfluidic channel. 


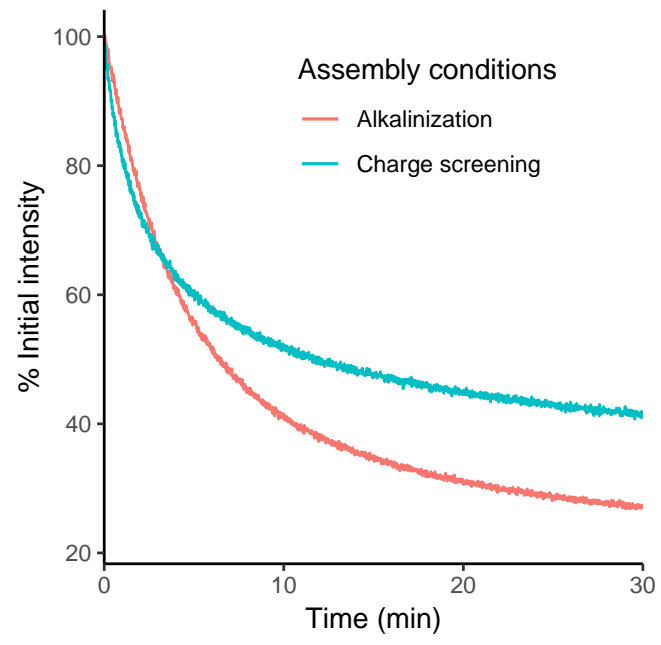

Figure S4: Kinetics for the quenching of pyreme monomer $\left(\lambda_{e x}=340 \mathrm{~nm}, \lambda_{e m}=420 \mathrm{~nm}\right)$ for $\mathbf{C P 1}(50 \mu \mathrm{M})$ in the presence of $\mathrm{CaC}_{2}(0.5 \mathrm{M}$, red line) or HEPES pH 8 (50 mM, red line).

\section{S4 Assembly in droplets triggered by alkalinization with HEPES}

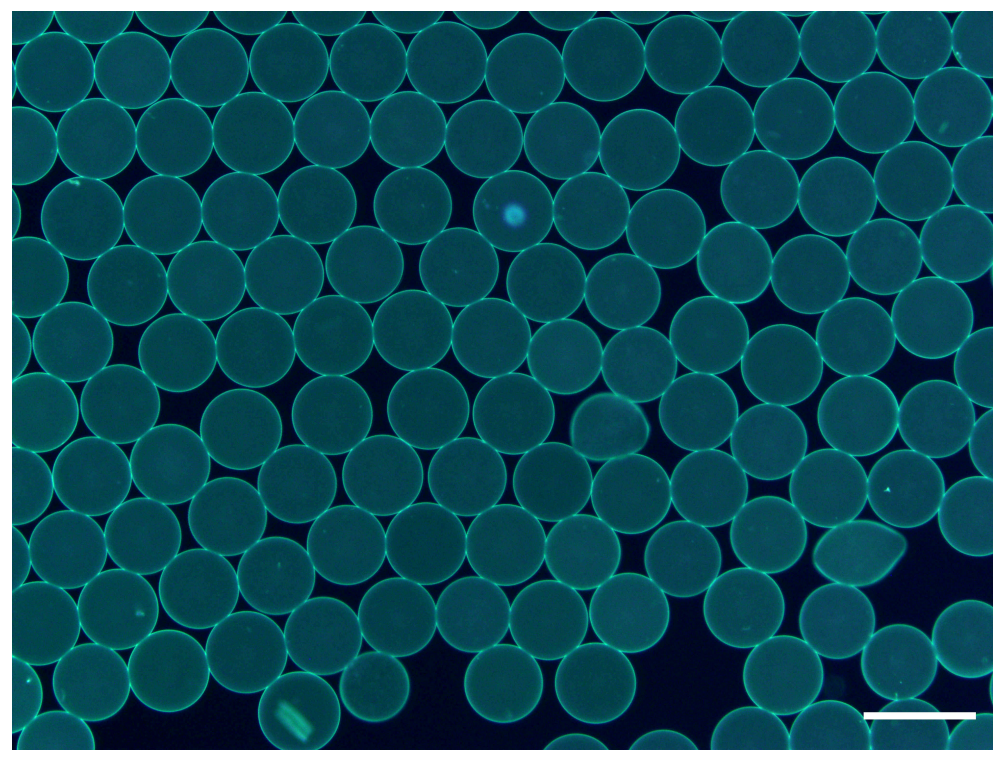

Figure S5: Droplets prepared by microfluidics. Conditions: $I_{C P 1}$ : CP1 $1 \mathrm{mM}$, milliQ water $\mathrm{pH} 4-5$, flow rate $200 \mu \mathrm{L} / \mathrm{h}$. $I_{T}$ : HEPES $50 \mathrm{mM} \mathrm{pH} 8$ as assembly trigger at flow rate of $100 \mu \mathrm{L} / \mathrm{h} . I_{\text {oil }}$ as described in the main text, flow rate 500 $\mu \mathrm{L} / \mathrm{h}$. Scale bar denotes $100 \mu \mathrm{m}$. 


\section{S5 Self-assembly of CP1 within water-in-oil droplets by picoinjection of $\mathrm{NaOH}$}

Droplets of disassembled CP1 were generated by flow focusing an aqueous solution of CP1 (1 mM) with HFE-7500 $3 \mathrm{M}^{\mathrm{TM}}$ Novec $^{\mathrm{TM}}$ containing Pico-Surf ${ }^{\mathrm{TM}}$ surfactant $(0.5 \% \mathrm{v} / \mathrm{v})$. Droplets were collected and then picoinjections of different volumes were carried out.

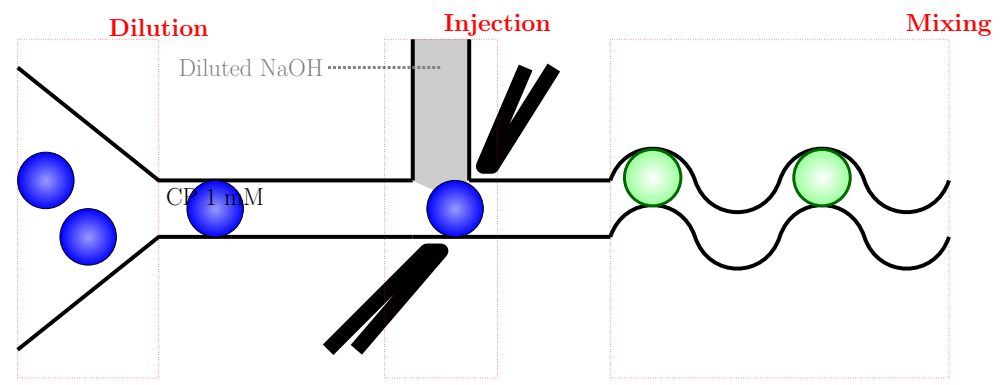

Figure S6: Schematic representation of the picoinjection device.
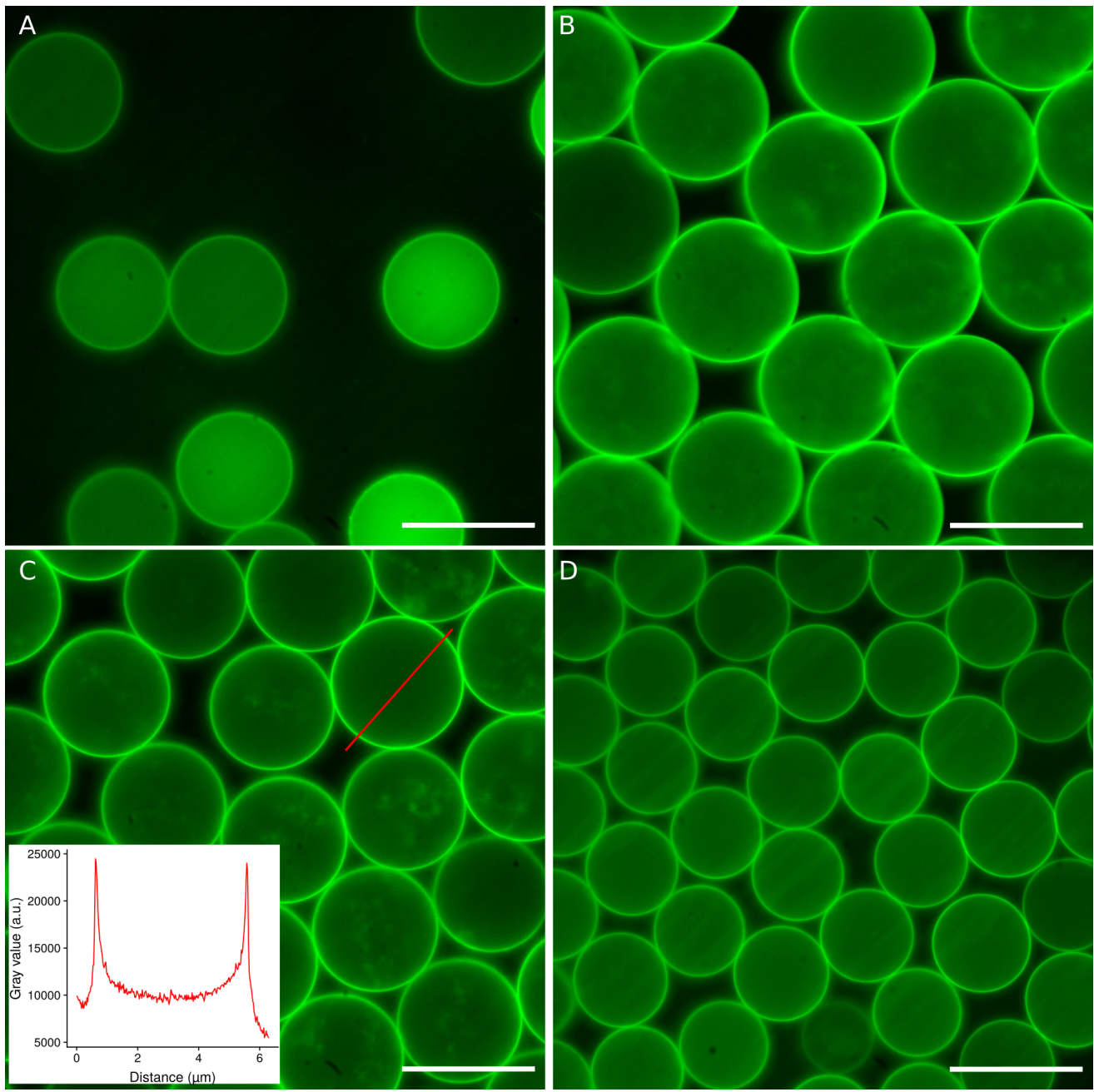

Figure S7: Self-assembly of CP1 within W/O droplets triggered by picoinjection of $\mathrm{NaOH}(13 \mathrm{mM})$. Picoinjections of the following volume were carried out: A) 5; B) 10; C) 20 and D) $30 \mu \mathrm{L}$. The insert in C) represents the profile of the droplet. Scale bars are $5 \mu \mathrm{m}$. Images are colorized from black and white originals. 


\section{S6 Confocal planes for droplets where fiber formation was triggered with $\mathrm{NaOH}$ or $\mathrm{CaCl}_{2}$}

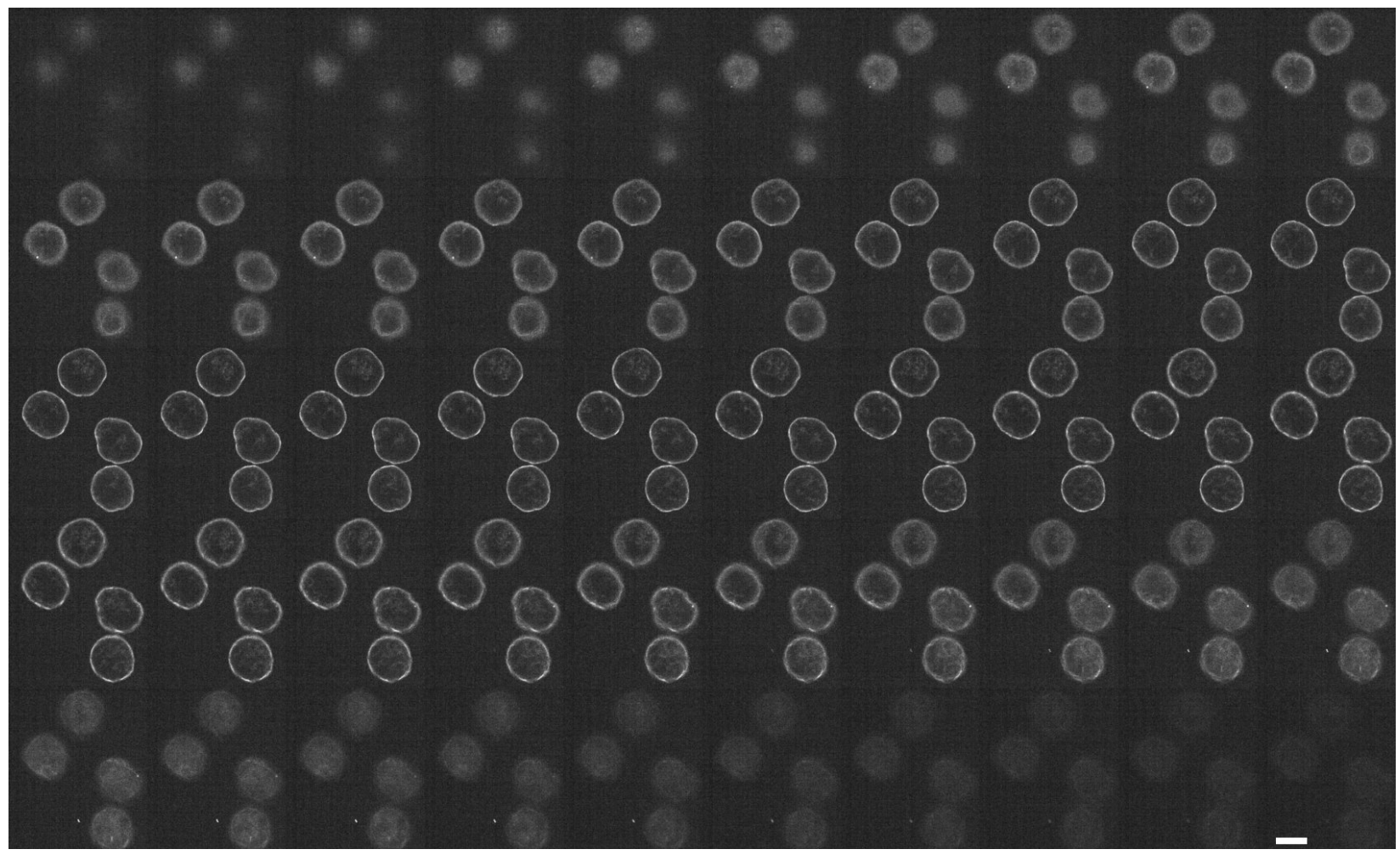

Figure S8: Confocal projections of droplets assembled using CP1 $(1 \mathrm{mM})$ in $I_{C P 1}$ at $200 \mu \mathrm{L} / \mathrm{h}$ and $I_{T} \mathrm{NaOH}(3.5 \mathrm{mM})$ at $100 \mu \mathrm{L} / \mathrm{h}$. Stack slices are ordered from left to right and from top to bottom. Scale bar is $50 \mu \mathrm{m}$.

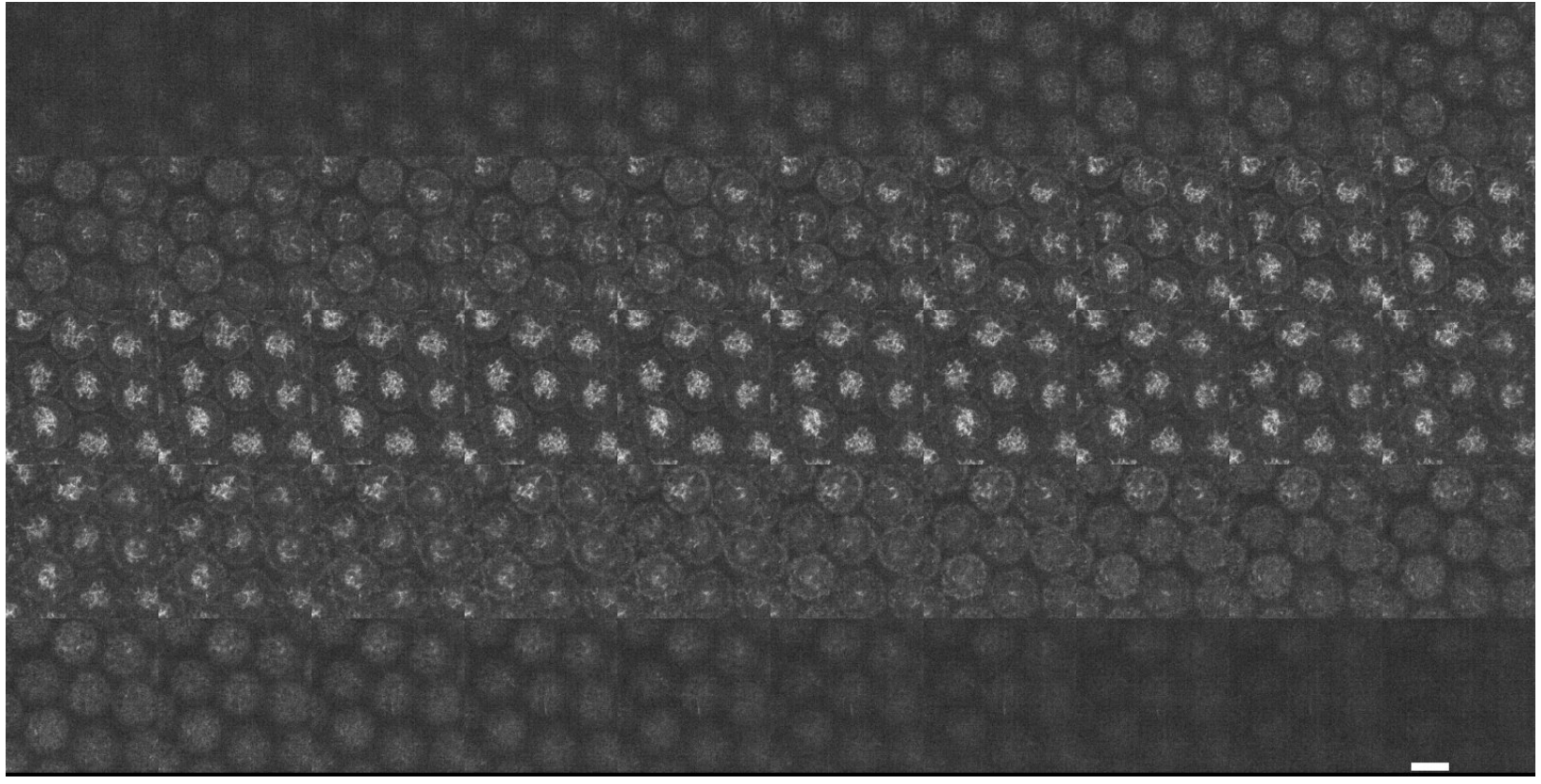

Figure S9: Confocal projections of droplets assembled using $\mathbf{C P 1}(1 \mathrm{mM})$ in $I_{C P 1}$ at $150 \mu \mathrm{L} / \mathrm{h}$ and $I_{T} \mathrm{CaCl}_{2}(1 \mathrm{M})$ at $100 \mu \mathrm{L} / \mathrm{h}$. Similar results were observed at $I_{T} 75 \mu \mathrm{L} / \mathrm{h}$. Stack slices are ordered from left to right and from top to bottom. Scale bar is $50 \mu \mathrm{m}$. 


\section{S7 Effect of flow rate changes using $\mathrm{NaOH}$ or $\mathrm{CaCl}_{2}$}
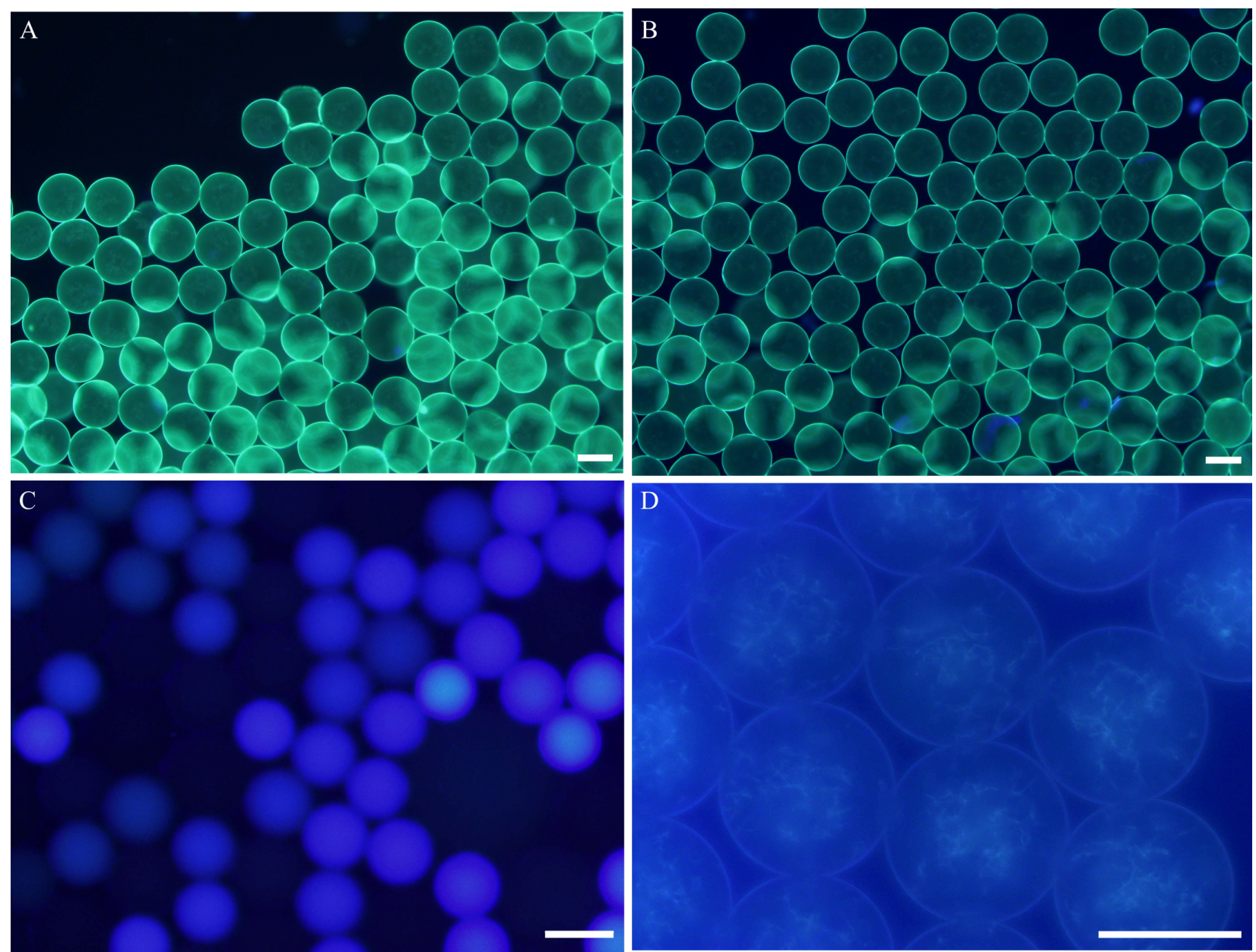

Figure S10: Epifluorescence images of droplets assembled using CP1 $(1 \mathrm{mM})$ in $I_{C P 1}$ and the following conditions: a) $150 \mu \mathrm{L} / \mathrm{h} \mathrm{CP1}$ and $100 \mu \mathrm{L} / \mathrm{h} \mathrm{NaOH}(3.5 \mathrm{mM})$ in $I_{T}$; b) $200 \mu \mathrm{L} / \mathrm{h} \mathrm{CP1} \mathrm{and} 100 \mu \mathrm{L} / \mathrm{h} \mathrm{NaOH}(3.5 \mathrm{mM})$ in $I_{T}$; c) 150 $\mu \mathrm{L} / \mathrm{h} \mathrm{CP1}$ and $10 \mu \mathrm{L} / \mathrm{h} \mathrm{CaCl}(1 \mathrm{M})$ in $I_{T} ;$ d) $150 \mu \mathrm{L} / \mathrm{h} \mathrm{CP1}$ and $100 \mu \mathrm{L} / \mathrm{h} \mathrm{NaOH}(1 \mathrm{M})$ in $I_{T}$. Scale bars are $50 \mu \mathrm{m}$. 


\section{S8 References}

[1] A. Méndez-Ardoy, J. R. Granja, J. Montenegro, Nanoscale Horiz. 2018, 3, 391-396.

[2] R. J. Best, J. J. Lyczakowski, S. Abalde-Cela, Z. Yu, C. Abell, A. G. Smith, Anal. Chem. 2016, 88, 10445-10451.

[3] J. Schindelin et al., Nat. Methods 2012, 9, 676-682.

[4] C. A. Schneider, W. S. Rasband, K. W. Eliceiri, Nat. Methods 2012, 9, 671-675.

[5] M. Nakakoshi, H. Nishioka, E. Katayama, J. Electron Microsc. (Tokyo) 2011, 60, 401-407.

[6] C. Stoffelen, R. Munirathinam, W. Verboom, J. Huskens, Mater. Horiz. 2014, 1, 595-601.

[7] A. Fuertes, H. L. Ozores, M. Amorín, J. R. Granja, Nanoscale 2017, 9, 748-753.

[8] CRC handbook of thermophysical and thermochemical data, CRC press Inc., 1994. 